\title{
EFEITO DO 1-METILCICLOPROPENO SOBRE A EMISSÃO DOS ÉSTERES VOLÁTEIS DE BANANAS AO LONGO DO AMADURECIMENTO
}

\section{Baraquizio Braga do Nascimento Junior*}

Departamento de Química e Exatas, Universidade Estadual do Sudoeste da Bahia, 45206-190 Jequié - BA / Departamento de Química Orgânica, Instituto de Química, Universidade Federal do Rio de Janeiro, 21945-970 Rio de Janeiro - RJ, Brasil

\section{Claudia Moraes Rezende}

Departamento de Química Orgânica, Instituto de Química, Universidade Federal do Rio de Janeiro, 21945-970 Rio de Janeiro RJ, Brasil

Antônio Gomes Soares e Marcos José de Oliveira Fonseca

Empresa Brasileira de Pesquisa Agropecuária, 23020-470 Rio de Janeiro - RJ, Brasil

Recebido em 20/6/07; aceito em 27/3/08; publicado na web em 26/8/08

\begin{abstract}
EFFECT OF 1-MCP ON ESTERS VOLATILES EMISSION OF BANANAS ALONG THE RIPENING. Fresh green bananas (Musa sp., subgroup Prata) were treated with a dose of only $90 \eta \mathrm{g} \mathrm{g}^{-1}$ of 1-MCP for 13 hours and the evolution of the volatile compounds along the ripeness was studied. A method to quantify the emission of esters was developed by cryogenic headspace and gas chromatography. Esters of acetate, butyrate, isobutyrate and isovalerate were found as major compounds. The application of the 1-MCP for 13 hours delayed the appearance of the coloration 8 of the peel for 3 days and decreased quantitatively in about $46 \%$ the total production of esters in the banana until the $15^{\circ}$ day of harvested.
\end{abstract}

Keywords: banana; 1-MCP; esters.

\section{INTRODUÇÃO}

O amadurecimento de bananas é acompanhado por uma mudança na coloração da casca de verde para amarela, amolecimento da polpa, conversão de amido em açúcares e desenvolvimento de aroma. ${ }^{1}$

O aroma é um importante contribuinte para a qualidade dos frutos e influencia a aceitabilidade pelo consumidor. Durante o amadurecimento, bananas produzem substâncias voláteis importantes para o aroma, tais como ésteres, álcoois, aldeídos e cetonas; sendo principalmente os ésteres os que contribuem para o odor característico do fruto. ${ }^{2}$

Os ésteres voláteis produzidos pelas frutas são formados pela reação entre álcoois e acetil-CoA derivados do metabolismo de ambos ácidos graxos e aminoácidos, dando origem a ésteres de cadeia normal e ramificada respectivamente. Estas reações são catalisadas pela enzima álcool acetil transferase. ${ }^{3}$ A Figura 1 mostra a estrutura do acetato de isoamila, um dos ésteres mais importantes encontrado no aroma da banana. ${ }^{4}$

Outras estruturas de ésteres importantes para o aroma da banana, como butirato de isoamila, isobutirato de isoamila e isovalerato de isoamila podem ser vistos no material suplementar, na Figuras 1S.<smiles>CC(=O)OCCC(C)C</smiles>

Figura 1. Estrutura do éster acetato de isoamila

Bananas, como qualquer outro fruto climatérico, têm um padrão de amadurecimento distinto. Este padrão de amadurecimento é afetado pelo etileno, um fito-hormônio gasoso produzido pelo fruto e também sintetizado pela indústria para regular e acelerar o processo de maturação dos frutos climatéricos. ${ }^{5}$ Porém, iniciado o amadurecimento a

\footnotetext{
*e-mail: barab@uesb.br
}

deterioração é rápida, a qual é uma preocupação tanto para o mercado como para o consumidor. Comercialmente, uma vez que as bananas são induzidas a amadurecer com aplicação de etileno, sua vida útil é de 3 a 5 dias, dependendo das condições de tratamento com etileno e temperatura de armazenamento. ${ }^{6}$ No entanto, se os frutos não forem induzidos com etileno, corre-se o risco de não amadurecerem.

1-Metilciclopropeno (1-MCP) é um opositor de etileno que vem sendo utilizado em diversas frutas, entre elas bananas, maçãs, goiabas, como um inibidor do amadurecimento. Golding et al., Jiang et al., ${ }^{8}$ Harris et al. ${ }^{9}$ e Macnish et al..$^{10}$ observaram o efeito do 1-MCP sobre bananas verdes antes da indução com etileno e mostraram atraso no amadurecimento, medindo coloração, produção de voláteis e amolecimento do fruto. Macnish et al..$^{10} \mathrm{e}$ Joyce et al. ${ }^{11}$ também realizaram estudos com o uso do 1-MCP em bananas aplicando 1-MCP antes da indução com etileno e não forneceram suficientes evidências para a indústria e consumidores que a qualidade do fruto maduro não foi alterada. Klieber et al. ${ }^{5}$ e Pelayo et al. ${ }^{6}$ avaliaram a exposição de bananas a várias concentrações de 1-MCP em diferentes estádios de amadurecimento, após 36-48 h de aplicação de etileno. Klieber et $a l .{ }^{5}$ relataram que, sob as condições testadas o 1-MCP estende por mais de 6 dias a $20^{\circ} \mathrm{C}$ a vida útil de bananas, mas afirmaram que é necessário avaliar o efeito de vários níveis de 1-MCP em bananas colhidas em diferentes estações. Pelayo et al. ${ }^{6}$ avaliaram o uso de diferentes concentrações do 1-MCP e concluíram que a eficiência do 1-MCP em atrasar amadurecimento em bananas parcialmente amadurecidas não é consistente para aplicação comercial.

$\mathrm{O}$ conhecimento das evoluções dos ésteres sob efeito do 1-MCP é fundamental para indicar se há alteração no aroma do fruto, como também para indicar se ocorreu ou não o amadurecimento do fruto. Segundo Willie e Fellman, ${ }^{3}$ o controle qualitativo e quantitativo do perfil dos ésteres voláteis em frutas representa um papel importante na determinação das características do aroma do fruto e presumivelmente pode determinar diferenças em cultivares. A produção dos compostos voláteis é uma característica de qualidade importante em 
muitos frutos e que precisa ser mais explorada. Portanto, este trabalho visa avaliar o efeito do 1-MCP sobre a produção de 15 ésteres voláteis importantes para o aroma da banana, formados durante o amadurecimento da fruta por 18 dias, a partir da fase climatérica e após aplicação comercial de etileno por $24 \mathrm{~h}$.

\section{PARTE EXPERIMENTAL}

\section{Frutos e tratamento com 1-MCP}

Bananas da cultivar 'Prata' (Musa sp., subgrupo Prata), pesando entre 87 e $250 \mathrm{~g}$, comprimento de 12 a $22 \mathrm{~cm}$, verdes e maturas fisiologicamente foram obtidas da Associação dos Produtores de Banana da cidade de Cachoeiras de Macacu, estado do Rio de Janeiro, Brasil, localizada à latitude $22,5^{\circ}$ sul, longitude $42,8^{\circ}$ oeste e altitude de $62 \mathrm{~m}^{12}$

De um lote proveniente de 10 caixas de banana climatizada comercialmente com atmosfera saturada de etileno por $24 \mathrm{~h} \mathrm{a} 15^{\circ} \mathrm{C}$ (20 kg por caixa), selecionaram visualmente os frutos que se encontravam no estádio de coloração 1 (fruto verde), descartando-se aqueles que estavam injuriados e amassados, de modo a obter as amostras durante o amadurecimento o mais próximo possível dos estádios de maturação, segundo carta de coloração. ${ }^{13}$

Após tratamento com etileno, as bananas foram constituídas em buquês com 6 frutos cada, divididas em dois lotes, fruto controle e fruto tratado com 1-MCP. O 1-MCP foi utilizado na formulação em pó, na concentração de $0,14 \%$ de ingrediente ativo. As bananas foram tratadas com uma dose única de $90 \eta g^{-1}$ de 1 -MCP (Smartfresh $\left.{ }^{\mathrm{tm}}\right)$. A aplicação do produto foi realizada em caixas de polietileno, com dimensões de 46 × 50 × $81 \mathrm{~cm}$, hermeticamente fechadas, nas quais os frutos permaneceram por $13 \mathrm{~h}$ conforme indicação do fabricante (AgroFresh Inc.). Após a aplicação do produto os frutos foram armazenados a uma temperatura de $24^{\circ} \mathrm{C} \pm 2$ e umidade relativa de $78,5 \%$.

A partir do $6^{\circ}$ dia após a colheita foram monitorados os ésteres voláteis por 18 dias, até quando os frutos se encontravam com as cascas totalmente amareladas com grandes áreas marrons (coloração estádio 8), de acordo com o sistema de classificação de bananas, ${ }^{13}$ então as análises foram concluídas.

\section{Amostragem dos voláteis pela técnica de headspace em "dedo frio"}

Os experimentos foram iniciados a partir do $6^{\circ}$ dia, pois segundo Tressl e Drawert ${ }^{14}$ e Morton e Macleod, ${ }^{4}$ o surgimento dos compostos voláteis em bananas se dá a partir do início da fase climatérica, alcançada após o $5^{\circ}$ dia a partir da colheita. A coleta dos compostos voláteis foi realizada por headspace em "dedo frio", em triplicatas e finalizados no $18^{\circ}$ dia.

$700 \mathrm{~g}$ de polpa das bananas 'Prata' amassadas foram transferidos para frascos erlenmeyers de $2 \mathrm{~L}$, com boca esmerilhada, fechados com um recipiente cilíndrico de vidro contendo gelo seco ("dedo frio"). Estes frascos foram colocados em um banho de água a temperatura de $22{ }^{\circ} \mathrm{C} \pm 2$ (a altura de $10 \mathrm{~cm}$ da base).

A camada de cristais formada na superfície do dedo frio foi raspada com espátula a cada $20 \mathrm{~min}$, por um período de $4 \mathrm{~h}$, para dentro de um bécher e lavada com $1 \mathrm{~mL}$ de $\mathrm{CH}_{2} \mathrm{Cl}_{2}$ (Tédia, EUA), pureza grau resíduo de pesticida. $\mathrm{O}$ material coletado foi transferido para um recipiente hermeticamente fechado e guardado em freezer a $0{ }^{\circ} \mathrm{C}$.

Após $4 \mathrm{~h}$, o extrato coletado foi tratado com $3 \mathrm{~g}$ de $\mathrm{NaCl}$, a fim de quebrar a emulsão formada entre a fase orgânica e a água. Após esse tratamento, o extrato orgânico foi seco com $4 \mathrm{~g}$ de $\mathrm{Na}_{2} \mathrm{SO}_{4}$ anidro.

A amostra isenta de água foi transferida para um balão volumétrico, concentrada com um fluxo de nitrogênio de $0,6 \mathrm{~mL} \mathrm{seg}^{-1}$ até 1 $\mathrm{mL}$ e adicionado o padrão interno $n$-octanoato de etila (Aldrich, EUA) na concentração de $100 \mu \mathrm{L} \mathrm{L}^{-1}$ e ajustado com $\mathrm{CH}_{2} \mathrm{Cl}_{2}$ em balança analítica até $\mathrm{o}$ peso de $1,20 \mathrm{~g}$.

\section{Cromatografia em fase gasosa acoplada à espectrometria de massas (CG-EM) e cromatografia em fase gasosa com detector de ionização por chama (CG-DIC)}

A análise por CG-EM foi realizada em um instrumento Agilent 5973 (Palo Alto, EUA), com impacto de elétrons a 70 eV, coluna DB-1 metilpolissiloxano (30 m x 0,25 mm x 1,0 $\mu \mathrm{m}$; Hewlett Packard Co., PA, EUA), modo de injeção sem divisão de fluxo por 0,5 min, gás carreador hélio com pressão constante de 4,5 psi, temperatura do injetor $240{ }^{\circ} \mathrm{C}$, temperatura da linha de transferência $280^{\circ} \mathrm{C}$. Programação do forno cromatográfico: temperatura inicial $35^{\circ} \mathrm{C}$ por $8 \mathrm{~min}$, rampa de aquecimento de $3{ }^{\circ} \mathrm{C} \mathrm{min}^{-1}$ até $150{ }^{\circ} \mathrm{C}$, isoterma de $5 \mathrm{~min}$.

A análise por CG-DIC foi realizada num instrumento HP-5890 (Hewlett Packard Co., PA, EUA), com detector de ionização por chama (DIC), coluna HP-1 de fase estacionária metilpolissiloxano ( $30 \mathrm{~m} \times 0,25 \mathrm{~mm} \times 1,0 \mu \mathrm{m})$, modo de injeção sem divisão de fluxo por 0,5 min, gás carreador hidrogênio com pressão de 14 psi, temperatura do injetor $240{ }^{\circ} \mathrm{C}$, temperatura do detector $280^{\circ} \mathrm{C}$. Programação do forno cromatográfico: temperatura inicial $35^{\circ} \mathrm{C}$ por $8 \mathrm{~min}$, rampa de aquecimento de $3{ }^{\circ} \mathrm{C} \mathrm{min}^{-1}$ até $150{ }^{\circ} \mathrm{C}$, isoterma de $5 \mathrm{~min}$.

Foi injetado $1 \mu \mathrm{L}$ dos extratos obtidos dos headspace da banana e suas repetições. Os ésteres presentes nas amostras foram identificados pela comparação direta dos tempos de retenção com os padrões sintetizados e pela fragmentação de seus espectros de massas.

A técnica adotada para a quantificação dos ésteres foi a padronização interna, realizada em triplicata. Foram preparadas 9 soluções padrão de concentrações conhecidas para cada éster de interesse, nas faixas de 0,04 a $405,14 \mu \mathrm{LL}^{-1}$, nas quais foi adicionado o padrão interno $n$-octanoato de etila (Aldrich, EUA) na concentração de $100 \mu \mathrm{L} \mathrm{L}^{-1}$.

A concentração dos voláteis na banana foi calculada pela razão entre as áreas integradas dos ésteres, obtidos das injeções de $1 \mu \mathrm{L}$ das amostras, adicionado o padrão interno de concentração conhecida (100 $\left.\mu \mathrm{L} \mathrm{L}^{-1}\right)$ e as áreas integradas dos padrões da curva de calibração de concentrações conhecidas, adicionadas também o padrão interno na mesma concentração. Desta forma, com o peso final de $1 \mathrm{~mL}$ do headspace e o peso das amostras dos frutos foi calculada a produção de cada composto $\left(\mu \mathrm{g} \mathrm{kg}^{-1}\right)$.

\section{Síntese dos padrões}

Os ésteres de interesse foram sintetizados via reação de Fischer. ${ }^{15}$ A natureza dos ésteres e seu grau de pureza (todos acima de $95 \%$ por CG) foram avaliados por espectrometria de ressonância magnética de ${ }^{1} \mathrm{He} \mathrm{e}^{13} \mathrm{C}$, espectrometria no infravermelho e CG-EM. Os ácidos carboxílicos e os álcoois utilizados foram obtidos da Merck (Alemanha) e Aldrich (EUA).

\section{Análise estatística}

Os resultados foram estatisticamente analisados pelo programa BioEstat 2.0, através da análise de variância (ANOVA), pelo teste de comparação de médias, utilizando-se os testes de testes de Tukey, F (Fisher) e t Student, todos com $\mathrm{P} \leq 0,05$, de acordo com Ayres et al. ${ }^{16}$

\section{RESULTADOS E DISCUSSÃO}

O extrato obtido pelo headspace estático em "dedo frio" das bananas apresentou álcoois, ácidos, aldeídos, cetonas, fenóis e especialmente os ésteres como constituintes majoritários pela análise por CG-EM.

Uma vantagem desta técnica de amostragem é a obtenção dos 
compostos voláteis sem a necessidade de aquecimento da matriz, muitas vezes prejudicial por gerar produtos de degradação. ${ }^{17} \mathrm{Em}$ bananas, altas temperaturas conduzem ao decréscimo da quantidade de voláteis e à formação de produtos fermentados. ${ }^{18}$

Ésteres da classe dos acetatos, butiratos, isobutiratos e isovaleratos, que representaram cerca de $70 \%$ da área dos voláteis por CG para a cultivar 'Prata', foram escolhidos para monitorar quantitativamente o processo de amadurecimento da banana sob efeito do 1-MCP.

As mudanças nas concentrações dos ésteres acetato de isoamila, butirato de isoamila, isobutirato de isoamila e isovalerato de isoamila são mostradas nas Figuras 2 a 5, respectivamente. A mudança nas concentrações dos outros ésteres das classes dos acetatos, butiratos, isobutiratos e isovaleratos também monitorados podem ser vistos no material suplementar, nas Figuras $2 \mathrm{~S}, 3 \mathrm{~S}, 4 \mathrm{~S}$ e $5 \mathrm{~S}$, respectivamente.

Os experimentos foram finalizados quando os frutos se encontravam com as cascas totalmente amareladas com grandes áreas marrons, isto é, quando se julgou na fase de cor da casca 8.

Os frutos sem tratamento com 1-MCP (frutos controle), apresentaram em geral um crescimento na concentração dos ésteres ao longo do amadurecimento, alcançando um máximo no $14^{\circ}$ dia póscolheita, as exceções foram os ésteres isobutirato de butila, onde esse máximo ocorreu no $7^{\circ}$ dia pós-colheita, acetato de butila no $10^{\circ}$ dia pós-colheita, butirato de butila, butirato de isoamila e isovalerato de

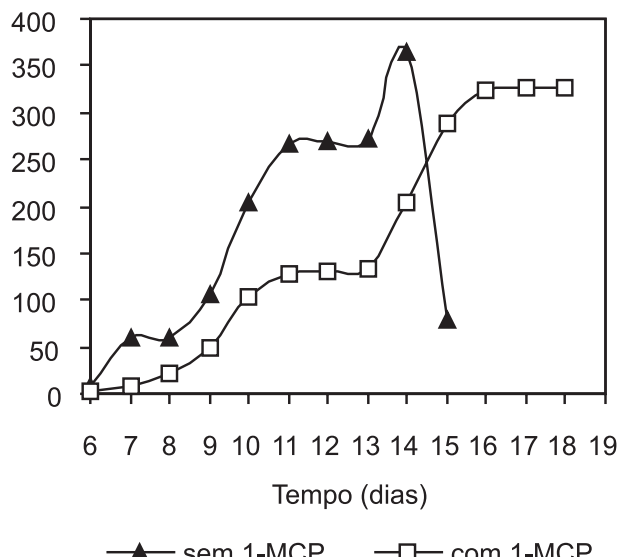

Figura 2. Concentração do éster acetato de isoamila ( $\mu \mathrm{g} \mathrm{kg}^{-1}$ de polpa) durante o amadurecimento de bananas 'Prata' com e sem tratamento com o 1-MCP. Os valores de produção são a média de 3 repetições realizadas dia a dia

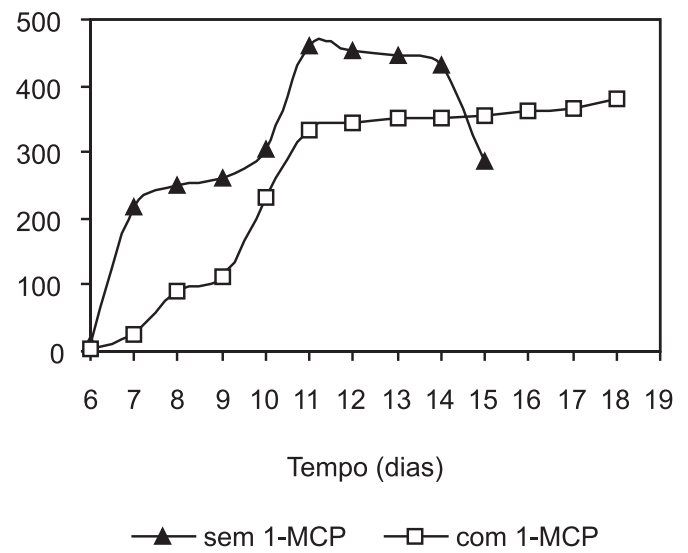

Figura 3. Concentração do éster butirato de isoamila ( $\mu \mathrm{g} \mathrm{kg}^{-1}$ de polpa) durante o amadurecimento de bananas 'Prata' com e sem tratamento com o 1-MCP. Os valores de produção são a média de 3 repetições realizadas dia a dia

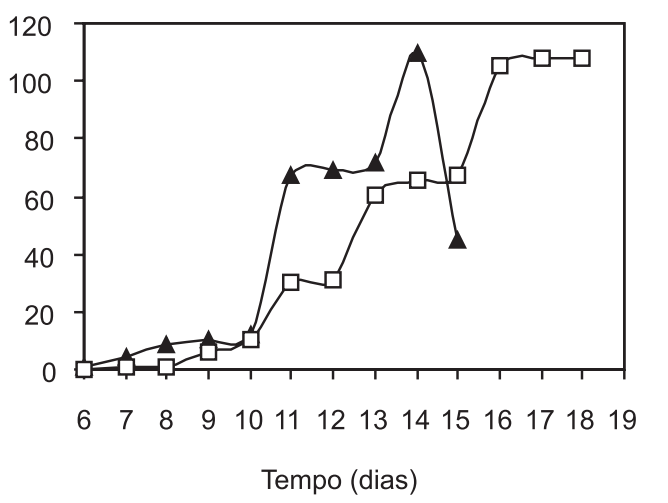

$\neg$ sem 1-MCP $\square-\operatorname{com} 1-\mathrm{MCP}$

Figura 4. Concentração do éster isobutirato de isoamila ( $\mu \mathrm{kg}^{-1}$ de polpa) durante o amadurecimento de bananas 'Prata' com e sem tratamento com o 1-MCP. Os valores de produção são a média de 3 repetições realizadas dia a dia

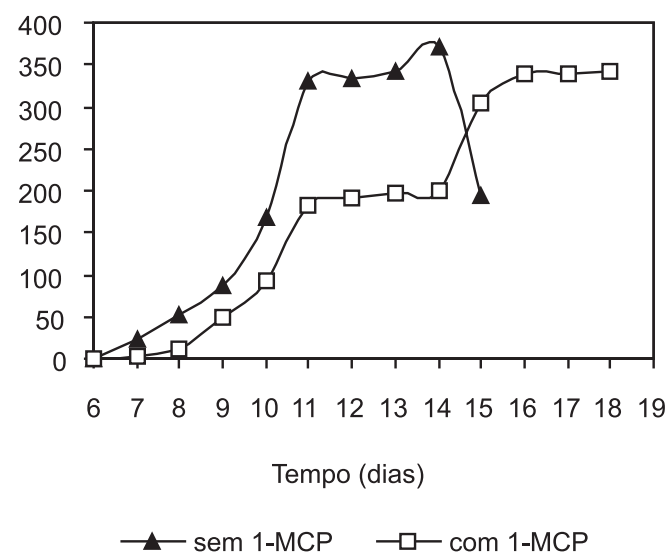

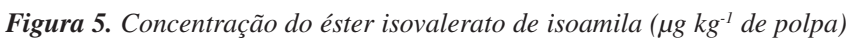
durante o amadurecimento de bananas 'Prata' com e sem tratamento com o 1-MCP. Os valores de produção são a média de 3 repetições realizadas dia a dia

etila no $11^{\circ}$ dia pós-colheita. $\mathrm{O}$ isobutirato de butila surgiu somente nos dias 6 e 7 após a colheita. Nesses experimentos, logo após o pico de produção dos ésteres, há uma tendência de diminuição na concentração. A exceção é o isobutirato de butila.

A aplicação do 1-MCP por $13 \mathrm{~h}$ atrasou o surgimento do estádio de coloração 8 da casca por 3 dias e diminuiu quantitativamente em aproximadamente $46 \%$ a produção total dos ésteres na banana 'Prata' até o $15^{\circ}$ dia pós-colheita. Nestes experimentos a curva de produção dos ésteres segue uma tendência de crescimento durante todo o amadurecimento dos frutos. As exceções são o butirato de butila e o isovalerato de etila. Esta tendência pode indicar que há mais substrato disponível para a produção de ésteres no fruto tratado com 1-MCP em relação ao fruto controle, mesmo quando estes frutos se encontram no estádio 8 de cor da casca. Também foi possível observar que, sob a ação do 1-MCP, a taxa de produção diária dos ésteres é bem menor (cerca de 3 vezes menos) quando comparada com a taxa de produção dos frutos não tratados.

Os ésteres produzidos durante $\mathrm{o}$ amadurecimento das bananas podem ser classificados em grupos. O grupo 1 inclui ésteres tais como acetato de etila, butirato de etila, isobutirato de isobutila, isobutirato de butila e isovalerato de isobutila, os quais tiveram as mais baixas taxas de produção (2 a $3 \%$ ) nas fases iniciais do amadurecimento, compreendido entre o $6^{\circ}$ e $10^{\circ}$ dias pós-colheita. Depois da aplicação com o 1-MCP aconteceu uma redução de aproximadamente $43 \%$ na sua produção nesta fase. 
O grupo 2 envolve ésteres que tiveram um aumento médio em suas taxas de produção (4 a $6 \%$ ) entre o $6^{\circ}$ e $10^{\circ}$ dias pós-colheita, como acetato de butila, isobutirato de isoamila e isovalerato de butila. Após a aplicação com 1-MCP houve uma redução de aproximadamente $50 \%$ na sua produção neste período.

O grupo 3 contém os ésteres acetato de isoamila e acetato de isobutila que tiveram uma alta taxa de produção $\left(8\right.$ a $9 \%$ ) entre o $6^{\circ}$ e $10^{\circ}$ dias pós-colheita. Após a aplicação do 1-MCP ocorreu uma redução de aproximadamente $50 \%$ na sua produção.

O grupo 4 inclui os ésteres butirato de butila, butirato de isoamila, butirato de isobutila, isovalerato de etila e isovalerato de isoamila, os quais tiveram uma taxa bastante alta de produção (18 a 35\%) entre o $6^{\circ}$ e $10^{\circ}$ dias pós-colheita. Depois da aplicação com o 1-MCP aconteceu uma redução de aproximadamente $47 \%$ na sua produção no período.

Destes resultados percebe-se que os grupos 2 e 3 foram os mais afetados pela aplicação do 1-MCP. Nestes grupos, encontram-se em ampla maioria ésteres ramificados derivados de aminoácidos, os quais podem também ter sido afetados pelo 1-MCP.

Apesar de não ter sido medido etileno nestes frutos ao longo do amadurecimento, sabe-se que o 1-MCP atua inibindo o etileno e que este age disparando o gatilho das transformações que ocorrem nos frutos durante o amadurecimento, sendo muito importante nas reações bioquímicas. A sua falta compromete toda a cadeia precursora dos voláteis, podendo ter afetado em maior grau os voláteis derivados de aminoácidos.

Song et al..$^{19}$ ao tratarem maçãs com 1-MCP afirmaram que o etileno foi o fator que limitou a produção de ésteres no fruto e que um aumento na atividade metabólica com produção de etileno era um pré-requisito para a estimulação do aroma das maçãs, porque ambos ésteres de cadeia normal e ramificada eram novamente produzidos.

Já Bauchot et al.$^{20}$ mostraram que melões transgênicos que produzem pouco etileno exibem substancial decréscimo na produção dos voláteis durante o amadurecimento e este declínio é mais marcante para aqueles voláteis que surgem via metabolismo de aminoácidos. As unidades estruturais encontradas nos esqueletos de carbono dos ésteres de banana 'Prata' aqui estudados são alguns de cadeia normal derivados do metabolismo de ácidos graxos (acetato de etila, butirato de etila, etc.) e, na sua ampla maioria (cerca de 73\%) são de cadeia ramificada derivados do metabolismo de aminoácidos (acetato de isoamila, butirato de isoamila, etc.), o que pode justificar os resultados encontrados.

Dentre os ésteres monitorados ao longo do amadurecimento existem alguns que contribuem mais fortemente para o aroma da banana. De acordo com a literatura, ${ }^{4,21,22}$ estes ésteres seriam o acetato de isoamila, acetato de isobutila, butirato de isoamila e isovalerato de isoamila, que sofreram reduções de 58, 41, 43 e $56 \%$, respectivamente, após aplicação com 1-MCP.

O 1-MCP altera o caminho que leva à formação dos voláteis. Esta alteração provoca mudanças quantitativas significativas na composição dos voláteis importantes para o perfil do aroma da banana. Contudo, após o efeito do 1-MCP no fruto, há uma restauração do perfil desses voláteis.

Em conclusão, a aplicação do 1-MCP na concentração de 90 ๆg $\mathrm{g}^{-1}$ por $13 \mathrm{~h}$ atrasou o surgimento do estágio de coloração 8 da casca por 3 dias e significativamente reduziu as taxas de produção dos ésteres voláteis. A inibição foi diferente para cada éster.

\section{MATERIAL SUPLEMENTAR}

Disponível gratuitamente em http://quimicanova.sbq.org.br, na forma de arquivo PDF. Nesta seção encontram-se a Figura 1S, que representa as estruturas dos ésteres importantes para ao aroma da banana, como também as Figuras $2 \mathrm{~S}, 3 \mathrm{~S}, 4 \mathrm{~S}$ e $5 \mathrm{~S}$ que representam as concentrações dos ésteres acetatos, butiratos, isobutiratos e isovaleratos monitorados ao longo do amadurecimento, respectivamente.

\section{AGRADECIMENTOS}

Ao Dr. W. S. P. Pereira da empresa AgroFresh Inc. pela doação do 1-MCP para utilização neste trabalho e à Associação dos Produtores de Banana da cidade de Cachoeiras de Macacu.

\section{REFERÊNCIAS}

1. Seymour, G. B.; Taylor, J.; Tucker, G.; Biochemistry of fruit ripening, $1^{\text {st }}$ ed., Chapman and Hall: London, 1993.

2. Ueda, Y.; Wendakoon, S. K.; Imahori, Y.; Ishimaru, M.; J. Agric. Food Chem. 2004, 52, 1615.

3. Willie, S. G.; Fellman, J. K.; J. Agric. Food Chem. 2000, 48, 3493.

4. Morton, I. D.; Macleod, A. J.; Food Flavours, $1^{\text {st }}$ ed., Elsevier Science Publishers: Amsterdam, 1990.

5. Klieber, A.; Bagnato, N.; Sedgley, M.; Int. J. Food Sci. Technol. 2003, 38, 745.

6. Pelayo, C.; Villas-Boas, E. V. de B.; Benichou, M.; Kader, A. A.; Postharvest Biol. Technol. 2003, $28,75$.

7. Golding, J. B.; Shearer, D.; Wyllie, S. G.; McGlasson, W. B.; Postharvest Biol. Technol. 1998, 14, 87; Golding, J. B.; Shearer, D.; McGlasson, W. B; Wyllie, S. G.; J. Agric. Food Chem. 1999, 47, 1646.

8. Jiang, Y.; Joyce, D. C.; Macnish, A. J.; Postharvest Biol. Technol. 1999a, 16, 187; Jiang, Y.; Joyce, D. C.; Macnish, A. J.; Plant Growth Regul. 1999b, 28, 77; Jiang, Y.; Joyce, D. C.; Macnish, A. J.; Plant Growth Regul. 2000, 19, 106.

9. Harris, D. R.; Seberry, J. A.; Wills, R. B. H.; Spohr, L. J.; Postharvest Biol. Technol. 2000, 20, 303.

10. Macnish, A. J.; Joyce, D. C.; Hofman, P. J.; Simons, D. H.; Reid, M. S.; Aust. J. Exp. Agric. 2000b, 40, 471; Macnish, A. J.; Joyce, D. C.; Hofman, P. J.; Simons, D.H.; Good Fruit and Vegetables 2000a, 10, 56.

11. Joyce, D. C.; Macnish, A. J.; Hofman, P. J.; Simons, D. H.; Reid, M. S.; Biology and Biotechnology of the Plant Hormone Ethylene II, $1^{\text {st }}$ ed., Kluwer Academic Publishers: Dordrecht, 1999.

12. http://www.sidra.ibge.gov.br, acessada em Fevereiro 2007.

13. Matsuura, F. C. A. U.; Folegatti, M. I. S.; Banana Pós - Colheita, $1^{\mathrm{a}}$ ed., Embrapa Mandioca e Fruticultura: Bahia, 2001.

14. Tressl, R.; Drawert, F.; J. Agric. Food Chem. 1973, 21, 560.

15. Vogel, A. I.;Vogel's Textbook of Pratical Organic Chemistry, $5^{\text {th }}$ ed., John Wiley \& Sons: New York, 1989.

16. Ayres, M.; Jr, A. M.; Lima Ayres, D.; Santos, A. S. dos.; BioEstat $2.0-$ aplicações estatísticas nas áreas das ciências biológicas e médicas, $2^{\text {a }}$ ed., Sociedade Civil Mamirauá/ MCT - CNPq: Belém, 2000.

17. Lopes, D. C.; Fraga, S. R.; Rezende, C. M.; Quim. Nova 1999, 22, 31.

18. Miranda, E. J. F; Nogueira, R. I.; Pontes, S. M.; Rezende, C. M.; Flavour Fragrance J. 2001, 16, 281.

19. Song, J.; Bangerth, F.; Postharvest Biol. Technol. 1996, 8, 259; Song, J.; Tian, M. S.; Dilley, D. R.; Beaudry, R. M.; HortScience 1997, 32, 536.

20. Bauchot, A. D.; Mottram, D. S.; Dodson, A. T.; John, P.; J. Agric. Food Chem. 1998, 46, 4787.

21. Nitz, S.; Berger, R. G.; Leupold, G.; Drawert, F.; Chem. Mikrobiol. Technol. Lebensm. 1984, 8, 121.

22. Mayr, D.; Märk, T.; Lindinger W.; Brevard, H.; Yeretzian C.; Int. J. Mass Spectrom. 2003, 223, 743. 


\section{EFEITO DO 1-METILCICLOPROPENO SOBRE A EMISSÃO DOS ÉSTERES VOLÁTEIS DE BANANAS AO LONGO DO AMADURECIMENTO}

Baraquizio Braga do Nascimento Junior*

Departamento de Química e Exatas, Universidade Estadual do Sudoeste da Bahia, 45206-190 Jequié - BA / Departamento de Química Orgânica, Instituto de Química, Universidade Federal do Rio de Janeiro, 21945-970 Rio de Janeiro - RJ, Brasil

Claudia Moraes Rezende

Departamento de Química Orgânica, Instituto de Química, Universidade Federal do Rio de Janeiro, 21945-970 Rio de Janeiro RJ, Brasil

Antônio Gomes Soares e Marcos José de Oliveira Fonseca

Empresa Brasileira de Pesquisa Agropecuária, 23020-470 Rio de Janeiro - RJ, Brasil<smiles>CCCC(=O)OCCC(C)C</smiles><smiles>CC(C)CCOC(=O)CC(C)C</smiles>

Isovalerato de isoamila

Figura 1S. Estruturas de alguns ésteres importantes para o aroma das bananas
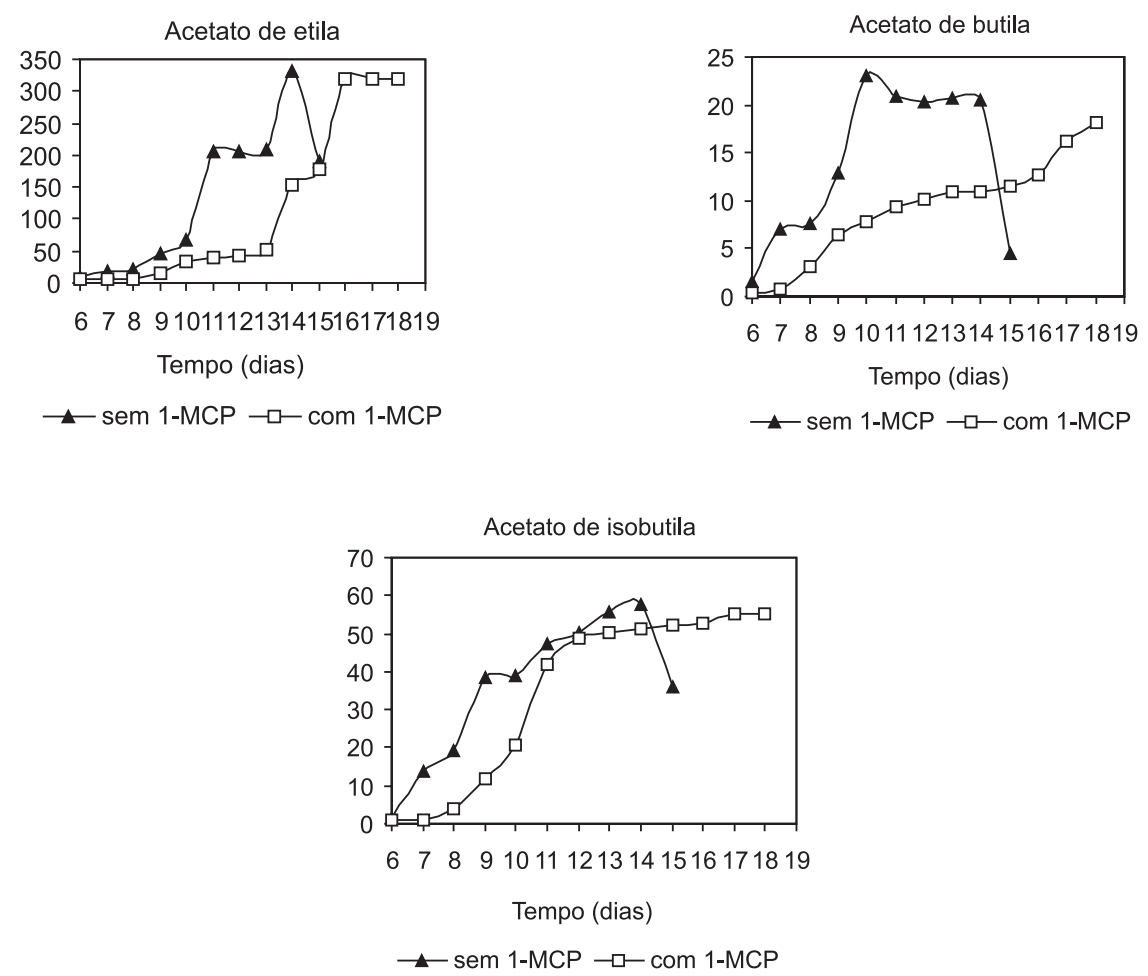

Figura 2 S. Concentração dos ésteres acetatos ( $\mu \mathrm{g} \mathrm{kg}$-1 de polpa) durante o amadurecimento de bananas 'Prata'come sem tratamento com o 1-MCP. Os valores de produção dos voláteis são a média de 3 repetições realizadas dia a dia 

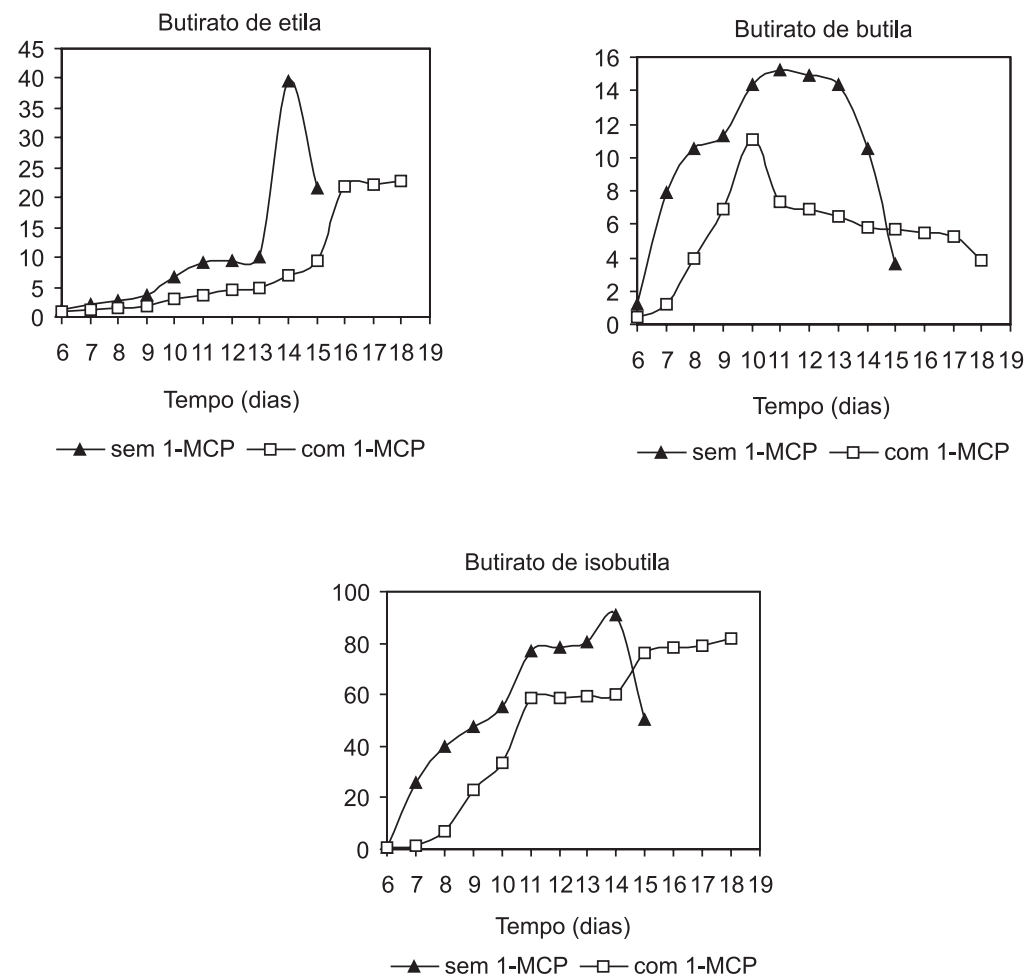

Figura 3S. Concentração dos ésteres butiratos ( $\mu \mathrm{g} \mathrm{kg}-1$ de polpa) durante o amadurecimento de bananas 'Prata' com e sem tratamento com o 1-MCP. Os valores de produção dos voláteis são a média de 3 repetições realizadas dia a dia
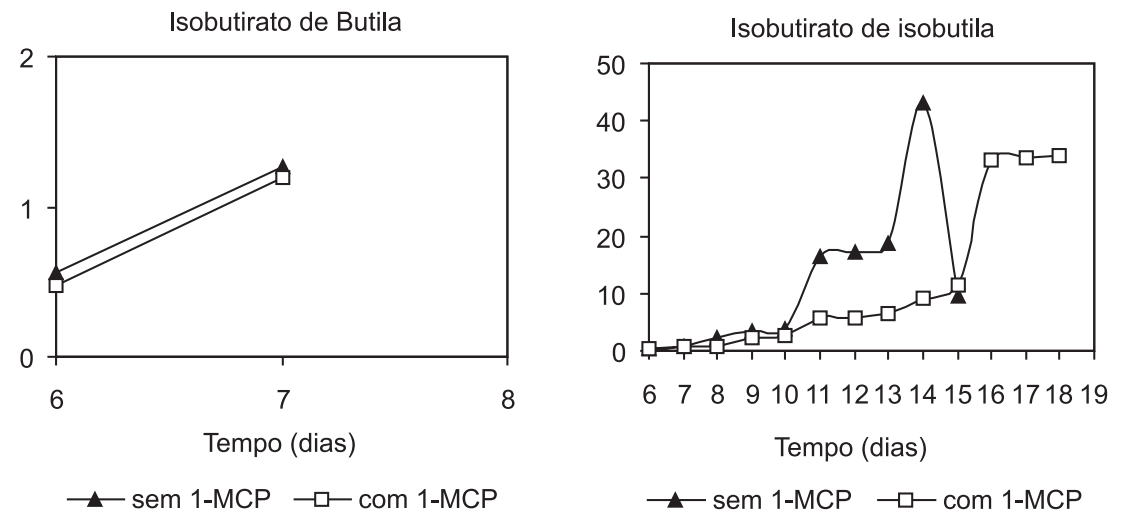

Figura 4S. Concentração dos ésteres isobutiratos ( $\mu \mathrm{g} \mathrm{kg}^{-1}$ de polpa) durante o amadurecimento de bananas 'Prata' com e sem tratamento com o 1-MCP. Os valores de produção dos voláteis são a média de 3 repetições realizadas dia a dia 

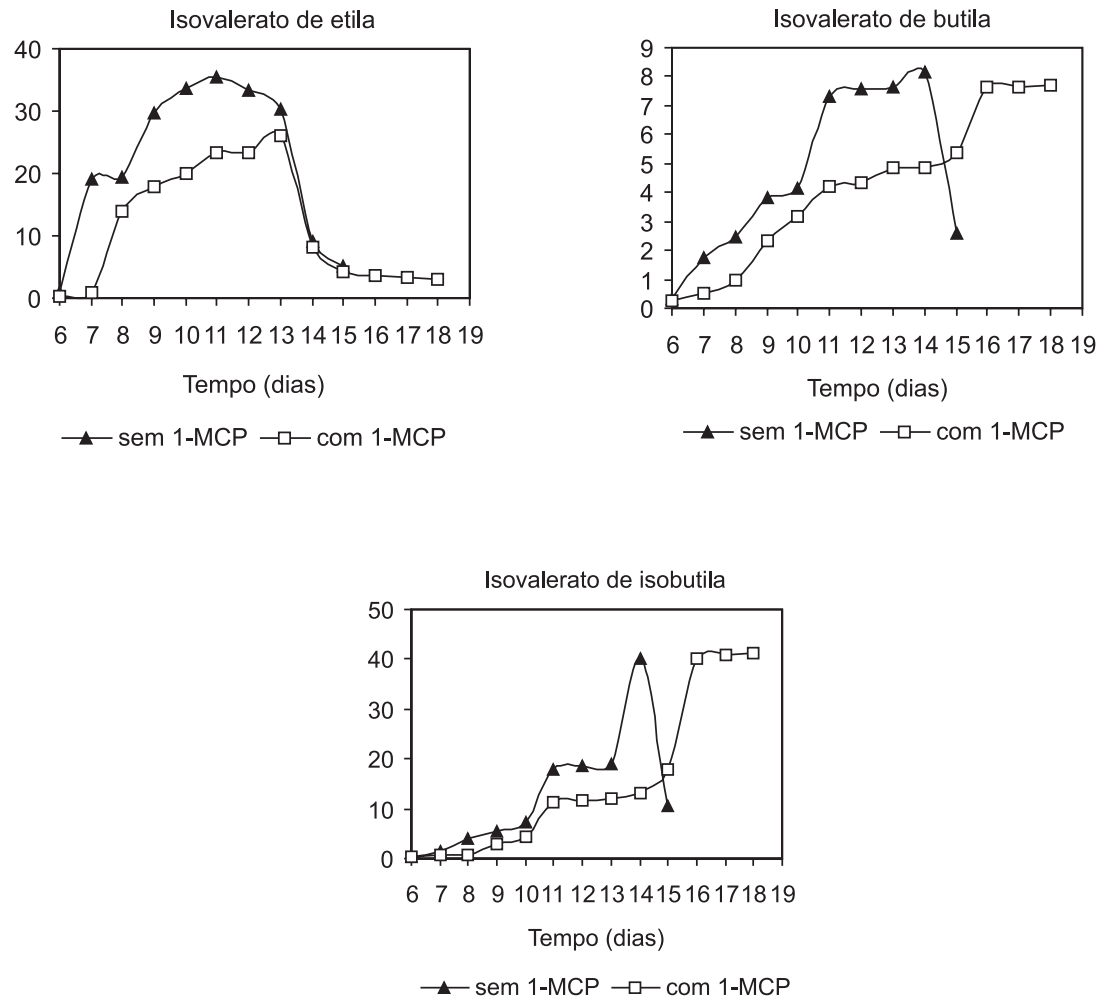

Figura 5S. Concentração dos ésteres isovaleratos ( $\mu \mathrm{g} \mathrm{kg}^{-1}$ de polpa) durante o amadurecimento de bananas 'Prata' com e sem tratamento com o 1-MCP. Os valores de produção dos voláteis são a média de 3 repetições realizadas dia a dia 